\title{
Development of PATS: A tool to assess professionalism
}

\author{
Dr humaira Fayyaz Khan ( $\sim$ humaira.fayyaz@riphah.edu.pk) \\ Riphah International University Islamic International Medical College https://orcid.org/0000-0002-4575-0724 \\ Dr. raheela Yasmeen \\ Riphah International University Islamic International Medical College \\ Shabana Ali \\ Riphah International University Islamic International Medical College \\ Tahira sadiq \\ Riphah International University Islamic International Medical College
}

\section{Research article}

Keywords: Professionalism, respect, altruism, honor and integrity, accountability, content validity, construct validity, cognitive pre-testing, and confirmatory factor analysis

Posted Date: October 18th, 2019

DOI: https://doi.org/10.21203/rs.2.14822/v2

License: (-) (i) This work is licensed under a Creative Commons Attribution 4.0 International License. Read Full License 


\section{Abstract}

Background: Professionalism has become a specific requirement for medical graduates because of dissatisfaction regarding their preparedness to adequately deal with the challenges of the medical world. It should be assessed as a competency in the final year of study using a valid and reliable instrument. The purpose was to develop and validate a tool to assess the development of professionalism in final year medical students in the local context to assess the readiness of medical graduates. Method: This was a mixed method study. Micro scenarios for the preliminary instrument were developed after a focus group meeting. These were validated using a 3-round modified Delphi technique by email. Twenty-four participants responded in the first round, and 15 in the second and third rounds. After the first round, relevance of the item was obtained. The content validity ratio was calculated after second round. Cut off value for items were approximated to be 0.6 and 0.73 for modification and 0.8 for item retention. The second round revised analysis was sent to participants for the third round and the content validity index average and universal agreement were calculated. Cognitive pretesting was performed. Cronbach's Alpha for reliability and Confirmatory factor analysis were carried out. Results: The focus group produced 46 microscenarios using a manual qualitative analysis. The first round of Delphi produced 35 items. On calculation of Content validity ratio 12 items were retained, 18 were revised and 5 were removed. Content validity index (I-CVI) and content validity scale (S-CVI) were 0.94 and 0.64 respectively. Pre-cognitive testing resulted in the modification of 4 items. The Confirmatory factor analysis was 4.1 . Cronbach's Alpha was 0.96 . Conclusion: The final instrument developed has a 27 item 5-point Likert scale. It has good content validity, reliability and acceptable construct validity. The strength of the instrument is in its process of development i.e. focus group discussion, the iterative Delphi rounds, cognitive pre-testing and piloting. It can be used to assess the development of professionalism in final year medical students. Keywords: Professionalism, respect, altruism, honor and integrity, accountability, content validity, construct validity, cognitive pre-testing, and confirmatory factor analysis

\section{Background}

Professionalism for a graduating student has been defined as "commitment to carrying out professional responsibilities, adherence to ethical principles and sensitivity to diverse patient populations" ${ }^{1,2}$ It encompasses those behaviors that serve to maintain patients' interest above physician self-interest and bridging the gap between medical field and society. ${ }^{3}$ Lapses in the professional behavior of medical students pose a challenge to the medical profession. ${ }^{4}$ The six domains of professionalism that the graduating doctor must show are: respect, accountability, commitment to excellence, altruism, integrity and compassion. ${ }^{5}$ An important aspect of undergraduate medical training is that it exposes students to the demands of real-life practice through a foundation of clinical competence, communication skills, and ethical understanding, upon which are built the domains of professionalism. ${ }^{6}$

Evidence from the literature suggests that professionalism should be deliberately assessed as assessments which motivate the individuals to learn ensuring quality in training programs. Methods assessing professionalism should bring together clinical competence, communication skills in medical practice; a few examples are situational judgment tests, ${ }^{7}$ case-based discussions, LAMPS, Mini-CEX etc. ${ }^{6}$ The situational judgment tests are widely used to evaluate interns to assess aspects of professionalism on a self reported basis.

Adopting a fresher perspective on professionalism can help create effective teaching and assessment strategies to support the development of professional behavior in medical students. ${ }^{8}$ It is important for the local institutions to define professionalism and develop tools to assess students according to the local culture and background. ${ }^{9,10,11}$ The aims of the study were to develop an instrument which is reliable and valid for assessment of professionalism in the undergraduate local medical context.

\section{Method}

This mixed method study with sequential qualitative and quantitative components was conducted in Islamic International Medical College, Riphah International University from February 2018 to August 2018 after obtaining ethical approval from the Ethical Review Committee. The tool developed is called 'Professionalism Assessment Tool for medical Students (PATS)

There were 4 phases of tool development, Figure 1:

1. Review of literature and questions for focus group.

2. Focus group discussion and preliminary tool development.

3. Conduction of three-round modified Delphi technique for consensus on item development.

4. Cognitive pretesting and piloting of the prepared tool to establish the reliability of the tool.

Phase 1: Following the guidelines from the AMEE guide no 87, a literature search was conducted. This identified the domains of professionalism and helped in development of questions for the focus group, ${ }^{12}$ which aimed to get an insight into the professional competence of a graduating medical student to measure the continuum of performance. The questions were validated by medical educationists.

Phase 2: Focus group Discussion and preliminary tool development

Nine participants who were certified medical educationists were selected. They had experience in curriculum and in assessment of undergraduate medical students. The recorded data was transcribed and analyzed manually by open coding to define concepts and categories of the domains of 
professionalism. A preliminary tool with 4-18 item statements around each domain was developed. The domain of respect had the maximum number of items. This tool had 46 mini-scenario statements overall.

Phase 3: A three round modified Delphi technique ${ }^{13}$ was employed for consensus on item statements.

\section{Delphi Round 1:}

Forty clinicians supervising final year medical students from Rawalpindi region were selected. A description of the project and a request to participate in the internet-based validation process through Google forms software was send.

Data collection method: The preliminary tool had 46 statements on a five-point Likert scale for relevance. Twenty-four experts responded in the first round. Relevance was rated on scale of 5 with 1 being "Not relevant" to 5 being "Highly relevant". Participants were given a period of 3 weeks for their responses.

Data analysis: Percentage responses and median score for each item were calculated as ordinal data and comments given by the panelists noted. A modified tool was prepared on Google forms software in light of the feedback.

\section{Delphi Round 2:}

The tool was recirculated to the participants, who were asked to assess how each of the mentioned elements is essential in the professional behavior of the medical student's local context. The "Content Validity Ratio" (CVR) was calculated for each item for content validation. This is a statistical instrument useful in the rejection and retention of items. CVR makes sure that those items are eliminated on which agreement among the participants might have occurred by chance. It is determined by the formula: ${ }^{14}$

$$
\mathrm{CVR}=(\mathrm{Ne}-\mathrm{N} / 2) /(\mathrm{N} / 2)
$$

Here $\mathrm{Ne}$ is the number of items rated essential by the panelist, $\mathrm{N}$ is the total number of the panelistsdivided by 2 . This is as a whole divided by the total number of the panelist divided by 2 .

\section{Delphi Third round:}

The expert panelists were sent a summarized rating of the items of the tool from the previous round. They were asked to revise their judgment or to specify the reason if they wanted to abstain. A 4-point ordinal rating was employed to avoid a neutral and uncertain midpoint. It represented the extent to which perceived overlap exists between capability to function in a defined job performance on the test.

After items had been identified for inclusion in the instrument item level, the "Content Validity Index" (CVI) was calculated. Item level CVI is the most common method for calculating the content validity and measures validity of individual items. However, another method to measure content validity of an instrument, known as Scale-level CVI (S-CVI), was employed to measure the overall validity of the overall scale of the instrument. S-CVI is calculated using two methods one requiring universal agreement among participants, known as S-CVI/UA. The other is S-CVI/Ave which was calculated by the number of items rated relevant by all DELPHI experts divided by the total number of items. ${ }^{13}$

Phase 4: Cognitive pretesting and Piloting of the prepared tool

Phase 4 a: Cognitive pretesting

A 27-item tool was finalized for Pre-cognitive testing. Ten faculty members were randomly selected through convenience sampling. Cognitive interviews were done after informed consent in a quiet and closed room.

\section{Data collection method:}

Interviews were conducted with concurrent verbal probing. The participants were asked to:

- Read out the tool items.

- Repeat the questions in own words.

- Clarify any specific term in the items of the tool that was unclear.

\section{Data analysis:}

The data was analyzed manually using pre-determined coding criteria to analyze responses. Most of the responses paralleled the findings of phase 3 . However, 4 items were modified.

\section{Phase $4 \mathrm{~b}$ : Piloting of the tool:}

\section{Data collection procedure:}

Data was collected using the tool to determine students' professionalism level. Twelve members of the faculty evaluated 228 clerkship students. 
Data analysis method:

\section{Factor analysis:}

Using M-Plus software, a statistical modeling program, the Construct Validity of the tool was measured by Confirmatory factor analysis (CFA). CFA determines the adequacy of a theoretical model in terms of how well it fits the observed data by evaluating the Root Mean Square Error of Approximation (RMSEA) Standardized Root Mean Residual (SRMR), Tucker-Lewis Index (TLI).

\section{Cronbach's alpha:}

The internal consistency of the final tool with its subscale was calculated by SPSS 22 employing Cronbach's alpha for reliability.

\section{Results}

The focus group produced a tool with 46 micro-scenarios (Table 1). It was validated through a modified Delphi technique and the first round resulted in 35 item statements. Table 2 shows the calculation of CVR for every item. Items with CVR of 0.6 were deleted. Those items with a score of 0.73 were modified and resent to the experts for revision/retention and those items having score of $\geq 0.8$ were retained without any change. Twelve items were retained, 18 were revised and 5 were removed. After the 3rd Delphi round, the Average Content validity scale (S-CVI/Ave) and the Content validity scale/Universal agreement (S-CVI/UA) were calculated (Table 3).

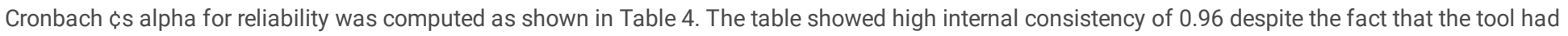
multifaceted elements. The inter-item correlation was high - it ranged from 0.71 to 0.933 . Table 5 showed the fit indices of the tool. The squared distribution with degree of freedom ( ) was less than $<5$.

\section{Discussion}

The main focus of the PATS tool was that it should be an indigenous tool, addressing the domains of Professionalism identified in the framework of ABIM in the local context. The purpose was that students could improve their professionalism as they graduated from medical college.

\section{Key findings}

This four-phase study identified domains of professionalism similar to those of the American Board of Internal Medicine. Characteristics identified are fairly similar to those found in other instruments for assessing professionalism, indicating that these are universal characteristics of medical professionalism which are useful in teaching and assessing for learning in the local context.

The construct of respect was observed to be most important by the participants in the local context. They were of the view that it should reflect in the overall approach of a clerkship student towards patients. This element is of utmost priority in south-Asian culture. Duty should be seen in students' activities, such as completing assignments on time. Effective communication skills are very important and are needed when dealing with peers, patients and seniors. The elements of Honor and Integrity should be displayed by the medical students as future doctors in their interactions and especially in high-pressure situations. In regard to excellence, it was agreed that the students need to maintain a proper dress code. They should not misbehave as they are representing a respectable profession. The construct of accountability was perceived as the least important.

\section{Relevance to similar tools in the literature}

The domains of professionalism have been identified in the literature. However, the study done by Nath did not specify domains. ${ }^{15}$ In this study the items were developed in a more methodical manner. The study by Nath, one of the initial studies carried out on professionalism, is a survey. That study compared the perceptions of professionalism among different professional groups. The survey had 29 circumstantial statements describing behaviors of professionals on components such as respect, accountability, honesty and integrity, empathy self-directed learning, skillful communication etc. In the present study, a focus group was conducted by the author to develop the items on the ABIM domain of professionalism, then they were validated through modified Delphi rounds. The developed tool was cognitively pre-tested and then it was piloted on a large sample of 1511 respondents. The study had three scales to rate the behaviors, but the present study has five scales to rate behavior.

Comparing the present study with other such studies, the objective was clear from the start: to develop a tool that would be able to assess professionalism in the local context. A tool developed by Al-Eraky in the Arabian context, though in a Muslim context, was different in the perspective that the tool was for the assessment of professionalism of medical students and interns. ${ }^{16}$ The developed tool in the present study is not intended to be used for the assessment of professionalism in interns or postgraduate trainees.

One of the methods for assessment of professional behavior is situational judgment tests which are personnel selection instruments that present junior doctors with clinical scenarios and possible responses to the situation. These have two types of instructions related to behavioral tendency and knowledge and the respondents are asked to evaluate the effectiveness of possible responses in a given situation. This method is a type of test, whereas the present instrument can be used by the faculty, patients or peers to assess the behavior of the student. ${ }^{7}$ 
The present study is in accordance with a study carried out for the development of a tool to assess professionalism in the Taiwanese context. That study was also carried out on 7th year senior medical students in Taiwan by Tsai and a 34-item tool was developed. ${ }^{17}$ The current study developed a 27 -item tool. The reference panel was not specified in the study by Tsai; however, the current study involved a panel of 9 participants for the focus group discussion. The methodology for piloting is not clearly given in Tsai's study, and the number of students on which it was piloted on was 133 . In contrast, in the present study, the tool was first of all evaluated through pre-cognitive testing and then modifications were made and then it was pilot tested on 228 students.

The Penn State Professionalism Questionnaire has 36 items and was developed with four parallel forms (Medical Students; Residents; Basic faculty and clinical faculty). ${ }^{19}$ The present tool targets the clerkship undergraduate medical students for feedback purposes.

\section{Content validity of the tool}

The content validity of the tool was calculated during and after the three modified Delphi techniques were performed. Content validity index (ICV-I), Content validity scale (S-CVI) and Content validity universal agreement (I-CVI/Avg) were determined and I-CVI/Avg was 0.94 . This aspect of the study is in accordance with a tool development study to evaluate the communication skills aspect of professionalism by Zamanzadeh Vahid et al in $2015 .{ }^{19}$ The S$\mathrm{CVI}$ in that study was 0.93 .18 The calculated values of the final tool of the present study were I-CVI/Avg (0.94) and I-CVI/UA (0.63) which is within the acceptable range.

For the clinicians and researchers, establishing the content validity of a tool is important. ${ }^{19}$ If it is not suitable then examining the behavior and attitude might not be reflective of the target population and the socio-cultural background.

\section{Construct validity of the tool}

In the present study there were six domains around which two to eight scales were developed. Most of the studies that have been conducted for the development of a professionalism tool have not included a confirmatory factor analysis. ${ }^{21}$

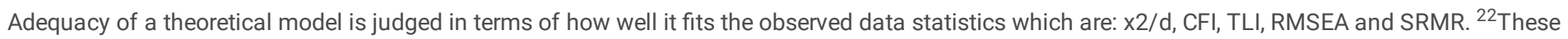
indices are used to determine the assessment of fitness indices and the researcher's theoretical justification for fitness to practice. Statistically, it is not appropriate to reject the tool. The RMSEA was 0.05 , which suggests a good fit as the cut off value is suggested at 0.06 values are good, indicating it is one of those indexes which are least affected by the sample size. The $x^{2} / d$ is less than 5 , suggesting a good model fit. The basic rule of thumb is that the fitness indices CFI and TLI should be $0.90 .{ }^{23}$ These are incremental fitness indices that compare the proposed model with a null model. The absolute fitness indices suggest an adequate fit for the developed instrument for the assessment of professionalism. The author reports indices of 0.76 and 0.73 for CFI and TLI in the present study. Weak correlations among observed variables might be a cause of this. The results for RMSEA and CFI in the present study are inconsistent as the two indices disagree. This might be because they evaluate by design the magnitude of the model's fit function from different perspectives so the values can differ. Moreover, the cut off values for theses indices are arbitrary. ${ }^{24}$

Upon comparing the CFA results of the present study with a study by Maat et al, a good model fit can be seen. However, that study was in the learning environment of high school students and had a sample size of 1887 which might be the reason for high CFI and TLI in that study. ${ }^{25}$

\section{Reliability}

The alpha reliabilities of most factors were good, except for altruism which was low but acceptable. ${ }^{26}$ One of the main reasons might have been in the understanding of the concept of altruism. The causes could have been in the translation of the concept of altruism identified during the focus group discussion.

\section{Practical Implications}

The methodological micro-scenario statement can help regulate the professional aspect of the behavior and attitude of the students towards better patient care through feedback at the undergraduate level, which improves the professionalism of the students. It can be modified and used to assess the professionalism of the students in basic sciences in the earlier years of medical training.

\section{Study limitations}

Limitations that needs mentioning is the sample size was small for the piloting of the tool and due to time constraints, longitudinal follow-up was not possible. As the data was collected in one institution generalizability of the tool is not well established.

\section{Recommendation}

The tool should be further piloted with increased sample size for context validation of the developed tool. To ensure generalizability it needs to be tested in other medical institutes of Pakistan. Outcome studies can be conducted to examine the effect of the developed tool on the professionalism of the students after its intervention.

\section{Conclusion}


The final tool developed is a 27 item, 5-point Likert scale. The strength of the tool was in its process of development, which included a focus group, iterative Delphi rounds, cognitive pre-testing and piloting. The tool has good facets and content validity. The calculated CFA provides evidence of reliability and construct validity. It is hoped that through the application of this tool in the clinical setting, professionalism of students can be assessed for the betterment of patient care.

\section{List Of Abbreviations}

American Board of Internal Medicine

\begin{tabular}{ll} 
CFA & Confirmatory Factor Analysis \\
\hline CFI & Confirmatory Factor Index \\
\hline CVR & Content validity Ratio \\
\hline FGD & Focus group discussion \\
\hline I-CVI & Content Validity Index \\
\hline I-CVI/UA & Content Validity Index/ Universal Agreement \\
\hline Mini-CEX & Mini-Clinical examination \\
\hline OSCE & Oral Structure Clinical Examination \\
\hline OSPE & Oral Structure Practical Examination \\
\hline P-MEX & Professional mini evaluation exercise \\
\hline RMSEA & Root Mean Square Error of Approximation \\
\hline S-CVI/Ave & Scale content validity Index Average \\
\hline SRMR & Standardized Root Mean Residual \\
\hline TLI & Tucker Lewis Index
\end{tabular}

\section{Declarations}

\section{Disclosure:}

This is a dissertation-based study which was approved for Masters in Health Profession Education.

\section{Ethics approval and consent to participate.}

\section{Ethics approval committee}

1. Dr. Muhammad Ayaz Bhatti ..chairman

HOD community medicine

2. Dr. Muhammad Farooq member

HOD Medicine

3. Dr. Rehan Ahmed Khan. member

4. Sundas Ambreen member

HOD Forensic Medicine

5. Shabana Ali member

Associate Professor Anatomy

Note:

This ethics approval committee is an institution review committee affiliated with Islamic International Medical college -RIPHAH International University.

Consent to participate: 
Written consent was obtained from the participants for taking part in the study.

\section{Consent for publication:}

Not applicable

\section{Availability of data and material}

The dataset generated or analyzed during this study is available from the author on reasonable request.

\section{Competing interests:}

There are no financial or non-financial competing interests.

\section{Funding:}

No funding was obtained for this study.

\section{Author's contribution:}

1. HFK:concieved the project, collected data and wrote the thesis.

2. RY:helped concieve and refine the project.

3. SA:helped collect data, and analysis of the data.

4. TS:helped collect data.

All the authors have read and approved the manuscript.

\section{Acknowledgements:}

We would like to acknowledge the help of Prof. dr Khurram Shazad and Mr. Daniyal for performing the confirmatory factor analysis.

\section{Reference}

1. Dent J, Harden RM, Hunt D. A practical guide for medical teachers. Elsevier health sciences; 2017 Apr 26.

2. Epstein RM, Hundert EM. Defining and assessing professional competence. Jama. 2002 Jan 9;287(2):226-35.

3. Jha V, Brockbank S, Roberts T. A framework for understanding lapses in professionalism among medical students: Applying the theory of planned behavior to fitness to practice cases. Academic Medicine 2016;1;91(12):1622-7.

4. Hur Y. Are there gaps between medical students and professors in the perception of students' professionalism level?-Secondary publication. Yonsei medical journal 2009; 31;50(6):751-6.

5. Robins LS, Braddock III CH, Fryer-Edwards KA. Using the American Board of Internal Medicine's "Elements of Professionalism" for undergraduate ethics education. Academic Medicine $2002 ; 1 ; 77(6): 523-31$

6. ABIM Foundation. American Board of Internal Medicine. Medical professionalism in the new millennium: a physician charter. Annals of Internal Medicine 2002; 5;136(3):243.

7. Christian MS, Edwards BD, Bradley JC. Situational judgment tests: Constructs assessed and a meta-analysis of their criterion-related validities. Personnel Psychology. 2010 Mar;63(1):83-117.

8. Chandratilake M, McAleer S, Gibson J. Cultural similarities and differences in medical professionalism: a multi-region study. Medical education. 2012 Mar;46(3):257-66.

9. Hodges BD, Ginsburg S, Cruess R, Cruess S, Delport R, Hafferty F, Ho MJ, Holmboe E, Holtman M, Ohbu S, Rees C. Assessment of professionalism: recommendations from the Ottawa 2010 Conference. Medical teacher 2011; 1;33(5):354-63.

10. Li H, Ding N, Zhang Y, Liu Y, Wen D. Assessing medical professionalism: a systematic review of instruments and their measurement properties. PloS one 2012;12(5):e0177321.

11. Nittur N,Kibble J.Current practices in assessing professionalism in United States and Canadian allopathic medical students and residents.Cureus.2017 May;9(5).

12. Artino Jr AR, La Rochelle JS, Dezee KJ, Gehlbach H. Developing questionnaires for educational research: AMEE Guide No. 87. Medical teacher. 2014 Jun 1;36(6):463-74.

13. Thangaratinam S, Redman CW. The delphi technique. The obstetrician \& gynaecologist. 2005 Apr;7(2):120-5.

14. Lawshe $\mathrm{CH}$. A quantitative approach to content validity 1. Personnel psychology. 1975 Dec;28(4):563-75. 
15. Nath C, Schmidt R, Gunel E. Perceptions of professionalism vary most with educational rank and age. Journal of dental education 2006; 1;70(8):82534.

16. Al-Eraky MM, Chandratilake M, Wajid G, Donkers J, van Merriënboer J. Medical professionalism: development and validation of the Arabian LAMPS. Medical teacher 2013;1;35(sup1):S56-62.

17. Tsai TC, Lin $\mathrm{CH}$, Harasym PH, Violato C. Students' perception on medical professionalism: the psychometric perspective. Medical teacher 2007 ;1;29(2-3):128-34.

18. Blackall GF, Melnick SA, Shoop GH, George J, Lerner SM, Wilson PK, Pees RC, Kreher M. Professionalism in medical education: the development and validation of a survey instrument to assess attitudes toward professionalism. Medical teacher 2007; 1;29(2-3):e58-62.

19. Zamanzadeh V, Ghahramanian A, Rassouli M, Abbaszadeh A, Alavi-Majd H, Nikanfar AR. Design and implementation content validity study: development of an instrument for measuring patient-centered communication. Journal of caring sciences $2015 ; 4(2): 165$.

20. Creswell JW, Creswell JD. Research design: Qualitative, quantitative, and mixed methods approaches. Sage publications; $2017: 12$.

21. Kelley KA, Stanke LD, Rabi SM, Kuba SE, Janke KK. Cross-validation of an instrument for measuring professionalism behaviors. American journal of pharmaceutical education 2011; 10;75(9):179.

22. Hoyle RH. Confirmatory factor analysis. InHandbook of applied multivariate statistics and mathematical modeling. Academic Press 2000;1: 465- 97.

23. Bentler PM. Comparative fit indexes in structural models. Psychological bulletin $1990 ; 107(2): 238$.

24. Lai K, Green SB. The problem with having two watches: Assessment of fit when RMSEA and CFI disagree. Multivariate behavioral research. 2016 May 3;51(2-3):220-39.

25. Maat SM, Adnan M, Abdullah MF, Ahmad CN, Puteh M. Confirmatory factor analysis of learning environment instrument among high performance school students. Creative Education $2015 ; 15 ; 6(06): 640$.

26. Harris J. Altruism: Should it be included as an attribute of medical professionalism?. Health Professions Education 2018;1;4(1):3 -8.

\section{Tables}

Table 1: Number of statements developed for the preliminary instrument

\begin{tabular}{|c|l|c|}
\hline Sr. No & Domains & No of statements \\
\hline 1. & Respect & 18 \\
\hline 2. & Altruism & 6 \\
\hline 3. & Honor and Integrity & 5 \\
\hline 4. & Duty & 4 \\
\hline 5. & Accountability & 6 \\
\hline 6. & Excellence & 7 \\
\hline & Total No & 46 \\
\hline
\end{tabular}

Table 2: Calculation of Content Validity Ratio for Content validity 


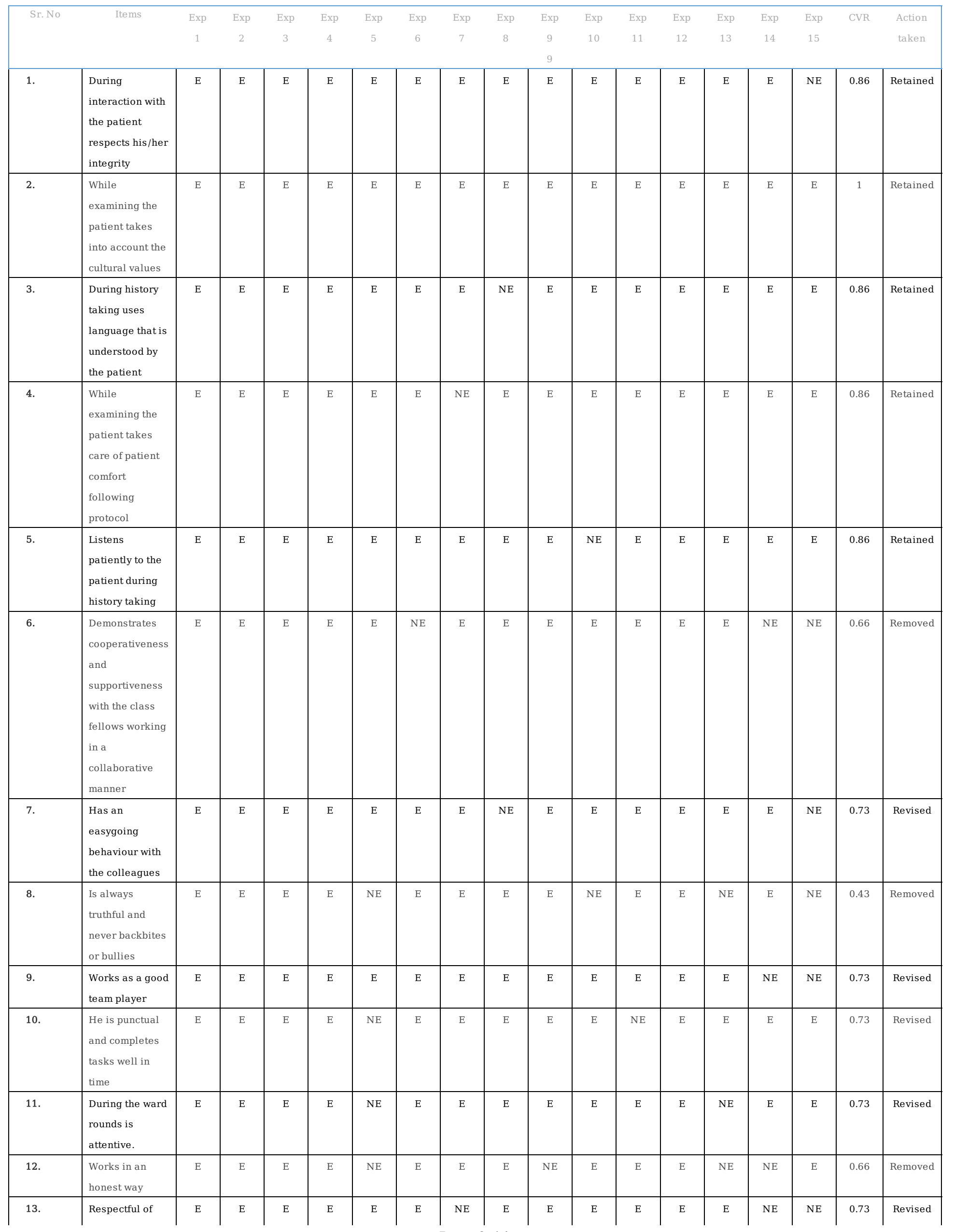




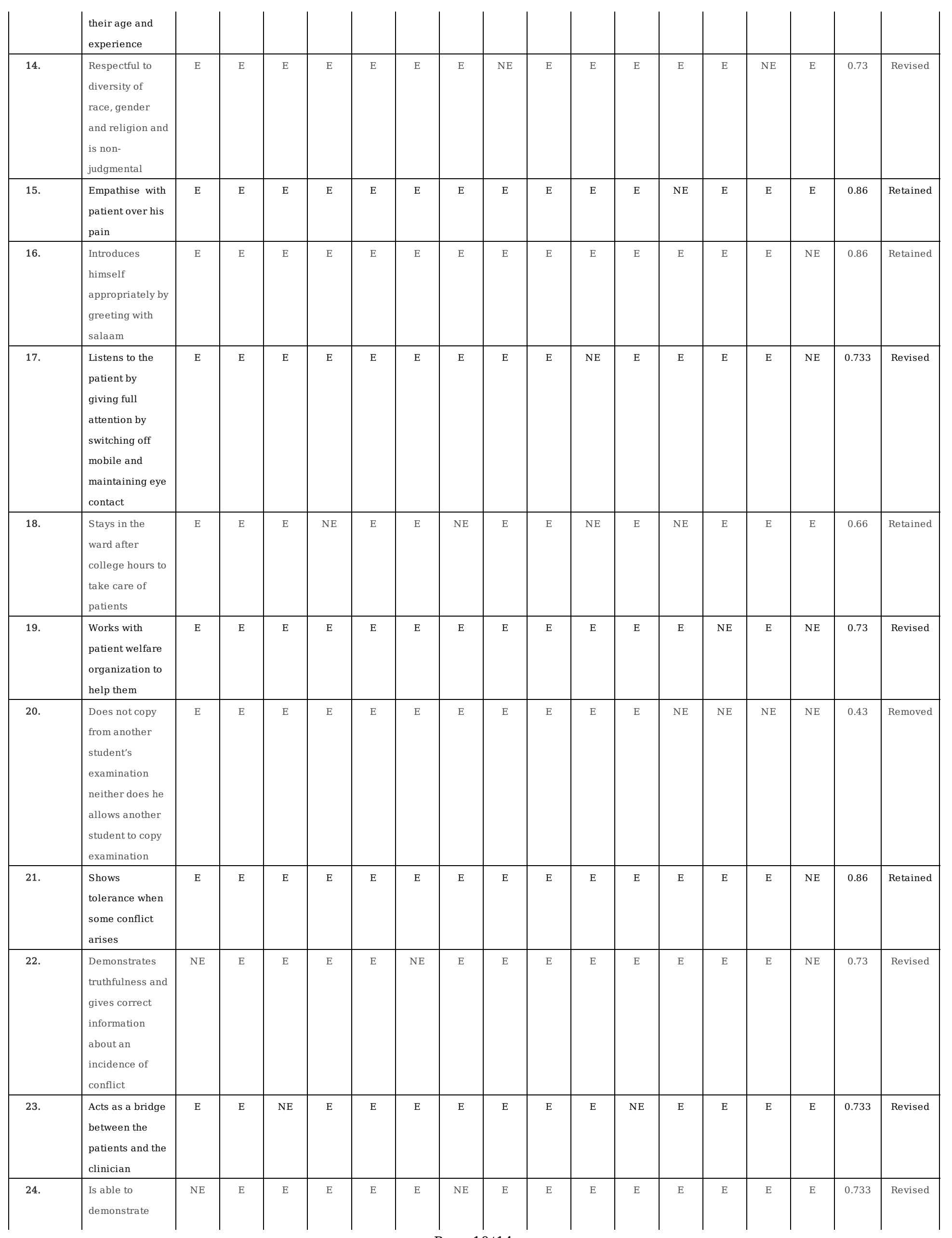

Page 10/14 


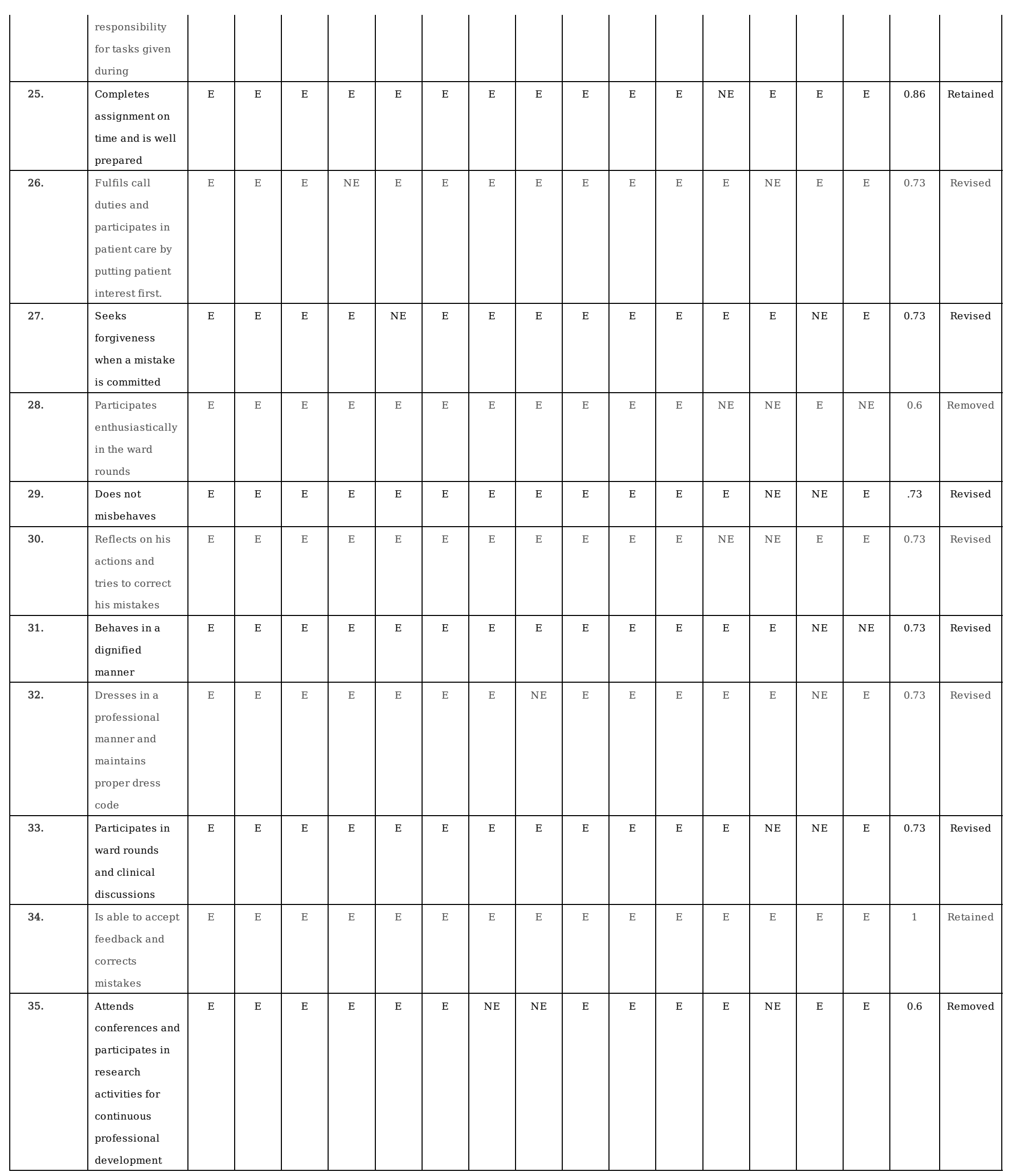

$\mathrm{E}=$ Essential, $\mathrm{NE}=$ Nonessential, $\mathrm{CVR}=$ Content validity Ratio 


\begin{tabular}{|c|c|c|}
\hline . & 0.96 & 0.63 \\
\hline
\end{tabular}

Table 4 : Cronbach's alpha for the instrument.

\begin{tabular}{|l|c|c|c|c|}
\hline Sr. No & Domains & Number of items & Cronbach's alpha & Overall Cronbach alpha \\
\hline 1. & Respect & 12 & .933 & \\
\hline 2. & Altruism & 2 & .741 & \multirow{2}{*}{0.96} \\
\cline { 1 - 2 } 3. & Honor \& Integrity & 2 & .80 & \\
\hline 4. & Accountability & 2 & .85 & \\
\hline 5. & Duty & 3 & .81 & \\
\hline 6. & Excellence & 4 & .87 & \\
\hline
\end{tabular}

Table 5 : Fit Indices of CFA Overall Model Fitness in comparison with the standard

\begin{tabular}{|c|c|c|c|c|c|}
\hline \multirow{2}{*}{ Fit indices } & \multicolumn{2}{|c|}{ Absolute } & \multicolumn{2}{c|}{ Incremental } \\
\cline { 2 - 6 } & Normed & RMSEA & SRMR & CFI & TLI \\
\hline Standard & $<5$ (significant p-value) & $<.06$ & $<.08$ & $>.92$ & $>.92$ \\
Sample > 250; indicators $<30$ & & & & & \\
\hline $\mathrm{N}=228 ; \quad$ Indicators:27 & $4.1 * * *$ & 0.05 & 0.06 & 0.766 & 0.735 \\
& $1295.9 / 309$ & & & & \\
\hline
\end{tabular}

$x^{2} / d f$. Squared distribution with degree of freedom

RMSEA: Root Mean Square Error of Approximation

SRMR: Standardized Root Mean Residual

TLI: Tucker-Lewis Index

CFI: Comparative fit index

\section{Figures}




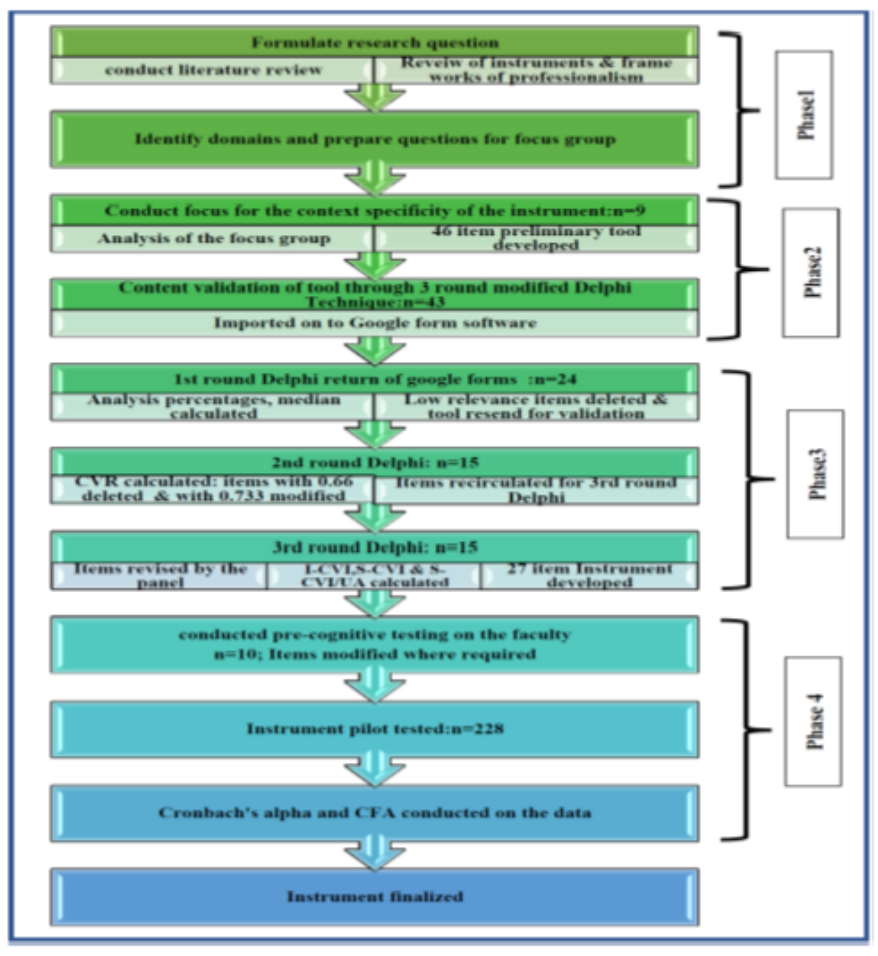

Figure 1

Flow chart for methodology CVR:Content Validity Ratio, I-CVI: Item content Validity Index, S-CVI: Content validity scale, S-CVI/UA: Content validity scale/Universal agreement, CFA: Confirmatory factor analysis 


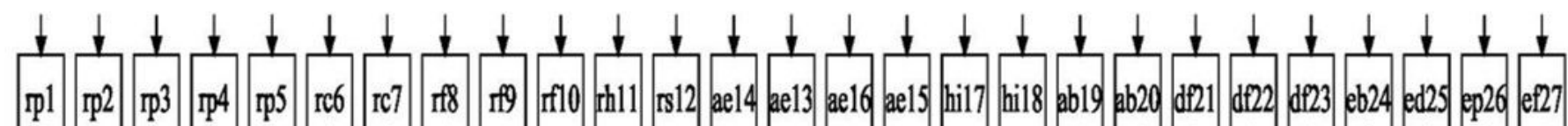

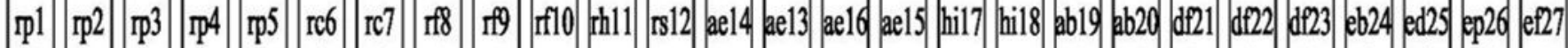
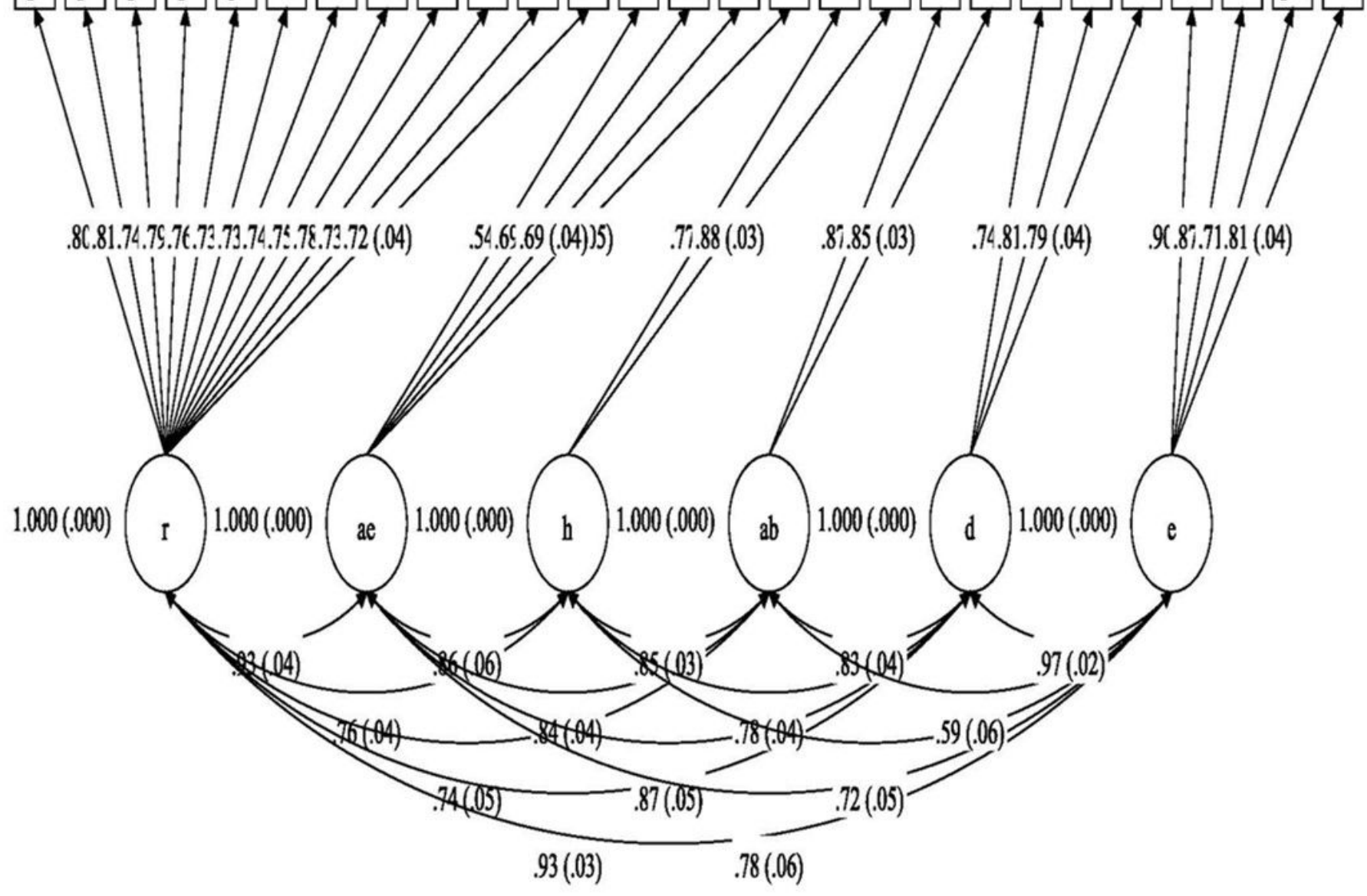

Figure 2

Model of Confirmatory Analysis 